\title{
Graphene/Activated carbon composite material for oxygen electrodes in
}

\section{lithium-oxygen rechargeable batteries}

Xing Xin, Kimihiko Ito, and Yoshimi Kubo*

GREEN, National Institute for Materials Science, 1-1 Namiki, Tsukuba 305-0044, Japan.

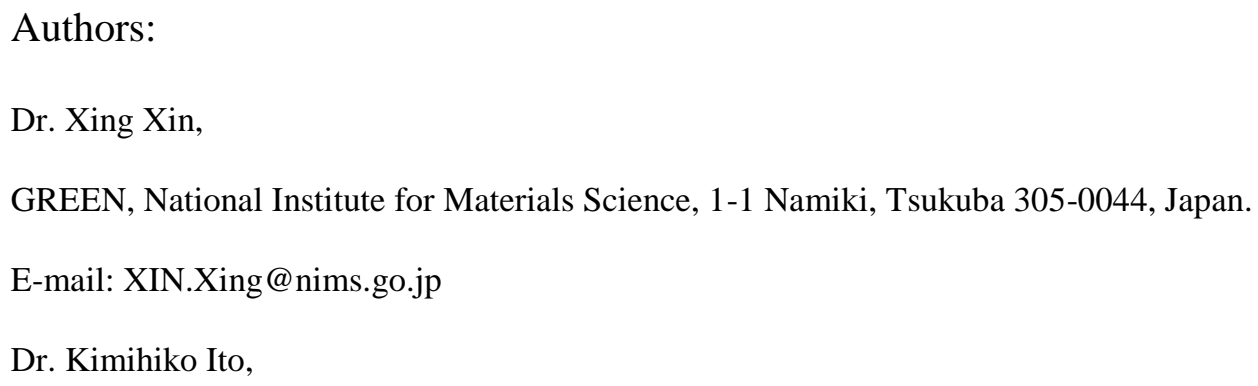

Authors:

Dr. Xing Xin,

GREEN, National Institute for Materials Science, 1-1 Namiki, Tsukuba 305-0044, Japan.

E-mail: XIN.Xing@nims.go.jp

Dr. Kimihiko Ito,

GREEN, National Institute for Materials Science, 1-1 Namiki, Tsukuba 305-0044, Japan.

E-mail: ITO.Kimihiko@nims.go.jp

* Corresponding authors:

Prof. Yoshimi Kubo

GREEN, National Institute for Materials Science, 1-1 Namiki, Tsukuba 305-0044, Japan.

Tel.: +81-029-860-4773

Fax: +81-029-860-4984

E-mail: KUBO.Yoshimi@nims.go.jp 


\section{Abstract}

To reduce the charge overpotential and improve the cyclability of Lithium-Oxygen $\left(\mathrm{Li}-\mathrm{O}_{2}\right)$ batteries, a novel carbon composite material consisting of graphene and activated carbon (G/AC) is developed for the oxygen electrode (cathode). In the G/AC, the graphene forms a three-dimensional (3D) network with good electrical conductivity and excellent mechanical strength and flexibility, while the AC layer on the graphene surface provides numerous meso/micropores with diameters of less than several nanometers that act as active sites (or nucleation sites) for the discharge reaction. The particle size of the discharge product $\mathrm{Li}_{2} \mathrm{O}_{2}$ becomes much smaller $(\sim 10 \mathrm{~nm})$, and the particles are distributed more homogeneously in the G/AC cathode, whereas toroidal particles as large as $100-200 \mathrm{~nm}$ occur in the pristine graphene cathode. The charge voltage for the G/AC cathode gradually increases from $\sim 3 \mathrm{~V}$ to $4 \mathrm{~V}$, while the voltage for the graphene cathode shows a steep increase to a plateau at $4.2-4.3 \mathrm{~V}$ and eventually exceeds 4.5 V. The G/AC cathode also exhibits much better cyclability than the graphene. These observations indicate that the refinement of the $\mathrm{Li}_{2} \mathrm{O}_{2}$ particles achieved by increasing the number of nucleation sites effectively lowers the charge overpotential and improves the cyclability of the $\mathrm{Li}^{-} \mathrm{O}_{2}$ batteries.

Key words: $\mathrm{Li}^{-} \mathrm{O}_{2}$ battery; graphene; porous structure; high surface area 


\section{Introduction}

Lithium-oxygen $\left(\mathrm{Li}-\mathrm{O}_{2}\right)$ batteries utilize ambient oxygen as the active material of the cathode, eliminating the need to store it in the cells. Batteries of this configuration can obtain an exceptionally high theoretical energy density that is $5-10$-fold greater than that of conventional Li-ion batteries [1-5]. Based on the fundamental reversible reaction $2 \mathrm{Li}^{+}+\mathrm{O}_{2}+2 \mathrm{e}^{-} \leftrightarrow \mathrm{Li}_{2} \mathrm{O}_{2}$, prototypical non-aqueous $\mathrm{Li}-\mathrm{O}_{2}$ batteries consist of a lithium metal anode, an electrolyte and a porous material for the cathode, which serves as a conducting matrix to accommodate the reaction products. During the discharge process, an oxygen molecule is reduced to form solidstate $\mathrm{Li}_{2} \mathrm{O}_{2}$, and the reverse reaction is caused by a subsequent charging process. Since first being introduced by Abraham and Jiang in 1996 [4], $\mathrm{Li}_{2} \mathrm{O}_{2}$ batteries have received substantial attention, and several efforts have been devoted to realizing their practical application. Despite their appreciable advantages, the main obstacles to developing $\mathrm{Li}_{-} \mathrm{O}_{2}$ batteries are associated with the large overpotential encountered during charging, which causes not only a low round-trip efficiency but also electrolyte degradation and poor cyclability.

Tremendous progress has been made in addressing these challenges, including the use of various catalysts [6-10]. However, the high cost of precious metals and the relatively low catalytic activities of other metal oxides have hindered further progress. Additionally, the relatively low electrical conductivity of most metal oxides leads to poor electrochemical performance. As an alternative approach, metal-free carbon-based materials have been investigated for many years because of their high conductivity, low cost and ease of fabrication. Over the past decades, various carbon materials, including carbon nanotubes [11-13], carbon fibers [14, 15], carbon aerogels [16], graphene [17-20], Super P [21], and ketjen black (KB) [22], have been employed as oxygen electrodes. Previous studies have revealed that carbon materials 
with highly conductive porous structures can provide efficient, rapid pathways for oxygen and electrons and can increase the specific capacity of $\mathrm{Li}-\mathrm{O}_{2}$ batteries [23, 24]. For those carbon cathodes, the discharge voltage is stable at $2.7 \mathrm{~V}$, which is slightly below the thermodynamic voltage of $2.96 \mathrm{~V}$, whereas the charge voltage is usually increased to $>4 \mathrm{~V}$.

To lower the charge overpotential, activated carbon (AC) materials with high surface areas have been investigated because they could influence the morphology of the discharge product via the active site $[25,26]$. However, in most cases, the AC cathode showed poor cyclability, most likely due to its discontinuous structure and poor electrical conductivity. Thus, designing a unique architecture for an AC-based surface material and employing a highly conductive matrix for the oxygen electrode should be crucial to accommodating $\mathrm{Li}_{2} \mathrm{O}_{2}$ and facilitating the transport of both electrons and oxygen. Graphene, a new type of two-dimensional (2D) carbon material, is a promising candidate for structural design because of its large surface area, good electrical conductivity, high electrochemical stability and excellent structural flexibility. It can be used as a fundamental building block to construct complex materials [27, 28].

In this work, a metal-free porous graphene/activated carbon (G/AC) composite material with ultrahigh surface area and countless nanopores was synthesized and used as an oxygen electrode for $\mathrm{Li}_{-} \mathrm{O}_{2}$ batteries. With the high surface area, the $\mathrm{G} / \mathrm{AC}$ material deliver the discharge capacity of $1800 \mu \mathrm{Ah} \mathrm{cm}{ }^{-2}$. The combination of graphene and AC provide good mechanical stability and numerous active site for formation of discharge products with size of $\sim 10 \mathrm{~nm}$. It was demonstrated that this G/AC material, which benefits from a high surface area and sheet-like structure, exhibits a lower charge voltage $(\sim 3 \mathrm{~V}$ to $4 \mathrm{~V})$ and longer cycle life than pristine reduced graphene oxide (RGO) and commercial $\mathrm{KB}$. 


\section{Experimental}

\subsection{Sample preparation}

Graphene oxide (GO) was prepared by the chemical exfoliation of natural graphite, following the modified Hummers method [29]; the experimental details are described in the supporting information. The final GO suspension was concentrated to $0.5 \mathrm{wt}$. \%. RGO powders were obtained by annealing freeze-dried $\mathrm{GO}$ at $850{ }^{\circ} \mathrm{C}$ for $3 \mathrm{~h}$ in an $\mathrm{Ar}+\mathrm{H}_{2}(4 \%)$ atmosphere.

The G/AC composite powders were prepared as follows. First, $30 \mathrm{~g}$ of GO suspension containing approximately $150 \mathrm{mg}$ of GO was diluted to $100 \mathrm{~cm}^{3}$ with deionized water, and then, $6 \mathrm{~g}$ of urea and $4.5 \mathrm{~g}$ of glucose were added. The mixture (precursor solution) was sonicated for $30 \mathrm{~min}$, transferred into a PTFE autoclave, and hydrothermally treated at $150{ }^{\circ} \mathrm{C}$ for $12 \mathrm{~h}$. The obtained sample was filtered and washed with deionized water three times and then freeze-dried for $20 \mathrm{~h}$. The resulting precursor powder was mixed with $\mathrm{KOH}$ at a weight ratio of 1:4 and chemically activated at $850{ }^{\circ} \mathrm{C}$ for $3 \mathrm{~h}$ in an $\mathrm{Ar}$ atmosphere. Then, the powder was washed with 10 wt. $\% \mathrm{HCl}$ solution and deionized water until the $\mathrm{pH}$ of the rinse was neutral. Finally, the suspension was freeze-dried to obtain the G/AC composite powder. Note that the G/AC ratio can be altered by changing the ratio of the precursors in the solution. Six samples with different G/AC ratios were prepared from precursor solutions with GO:urea:glucose weight ratios of $0.15: 6: 4.5,0.15: 5: 4,0.15: 4: 3.5,0.15: 3: 3,0.15: 2: 2.5$ and $0.15: 1: 2$. According to the increasing weight ratio of GO in the precursor solutions, the G/AC samples were denoted as G/AC-1, G/AC-2, G/AC-3, G/AC-4, G/AC-5 and G/AC-6, respectively. The approximate amounts of AC are listed in Table $\mathrm{S} 1$ in the supplementary material.

\subsection{Sample characterization}


The morphologies and structures of the cathode were analyzed using an S-7800 field-emission scanning electron microscope (FESEM, JEOL) and a JEM-ARM 200F transmission electron microscope (TEM, JEOL). X-ray photoelectron spectroscopy (XPS) measurements were performed using a VersaProbe II (ULVAC-PHI) scanning XPS microprobe. X-ray diffraction (XRD) measurements were carried out on a New D8 ADVANCE (Bruker) powder X-ray diffractometer. In these measurements, air-isolated sample holders were used for the discharged samples to prevent reactions with air. The surface areas were measured by the Brunauer-EmmettTeller (BET) method using a 3Flex Surface Characterization Analyzer (Micromeritics Instrument). The pore size distributions were calculated using the Barrett-Joyner-Halenda (BJH) method.

\subsection{Electrochemical tests}

Electrochemical tests were carried out under flowing oxygen gas in test cells. The test cell consisted of a lithium metal anode (16 $\mathrm{mm}$ in diameter and $0.2-\mathrm{mm}$ thick), a glass-fiber separator (GF/A, Whatman) and a carbon-paper cathode (16 mm in diameter and $0.2 \mathrm{~mm}$ thick, TGP-H060, Toray) coated with KB (EC600JD, Lion), RGO or G/AC powders. These powders were coated by making a paste containing $10 \mathrm{wt}$ \% polyvinylidene difluoride (PVDF) binder in NMP

solvent. The loading of $\mathrm{KB}, \mathrm{RGO}$ or $\mathrm{G} / \mathrm{AC}$ on the carbon paper was $1 \pm 0.2 \mathrm{mg} \mathrm{cm}^{-2}$. The electrolyte was composed of $1-\mathrm{M} \mathrm{LiCF}_{3} \mathrm{SO}_{3}$ in tetraethylene glycol dimethyl ether (TEGDME). Specific capacities and current densities were calculated according to the projected area of the cathode. Discharge and charge profiles were collected using a battery discharge-charge system (HJ1001SD8, Hokuto Denko).

\section{Results and discussion}


The microstructures of RGO, KB and G/AC-1 were observed by TEM and FESEM. As seen in Fig. 1a, the RGO powders present a typical sheet-like structure with lateral dimensions of several micrometers. The sheets appear to be fairly thin according to the TEM image in Fig. 1b. The RGO powders are generally composed of randomly aggregated sheets that are curled and loosely packed to generate a porous structure with cavities that are several tens or hundreds of nanometers in size. The morphology of G/AC-1, as shown in Fig. 1c, presents a rough surface. Most of the observed G/AC-1 maintains the flexible sheet-like structure, but the layer thickness is increased over that of pristine RGO nanosheets. This suggests that the G/AC-1 nanosheets are
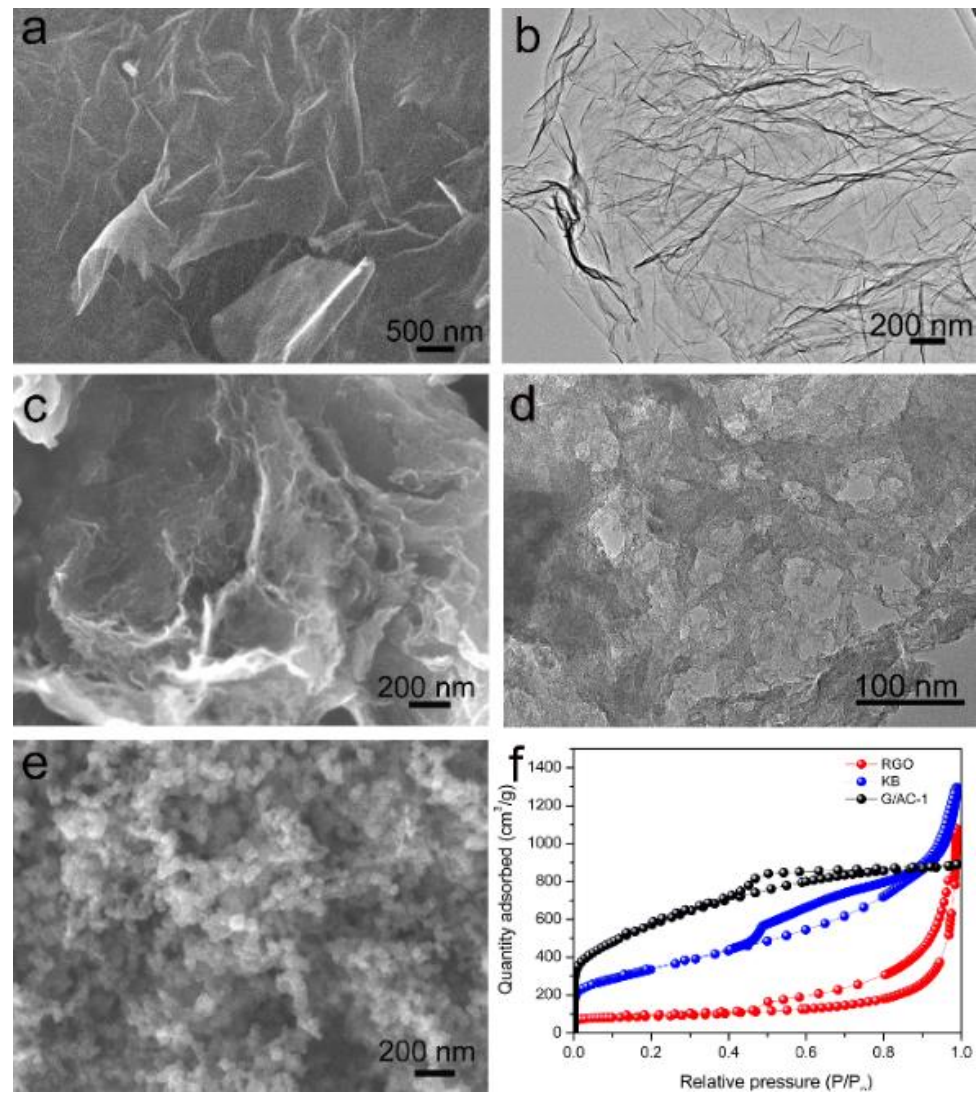

Fig. 1. FESEM (a) and TEM (b) images of RGO nanosheets. FESEM (c) and TEM (d) images of G/AC-1. (e) FESEM image of KB. (f) Corresponding nitrogen adsorption-desorption curves of RGO, KB and G/AC-1. 
densely covered with pyrolytic carbon originating from the glucose and urea. The TEM image in Fig. 1d clearly demonstrates that G/AC-1 presents a nearly agglomerated porous structure with numerous open mesopores. Fig. 1e reveals that $\mathrm{KB}$ consists of tiny particles that are approximately $30-50 \mathrm{~nm}$ in size. The particles aggregate to form a porous structure with a pore size similar to that of their particles. $\mathrm{N}_{2}$ adsorption-desorption isotherm measurements were carried out to evaluate the specific surface areas and microstructures of all the three samples. As shown in Fig. 1f, all of the samples exhibit a typical type IV isotherm. The initially flat region of the RGO isotherm indicates that there are almost no micropores in the structure. From the pore size distribution (Fig. S1a), it is apparent that the main pore size of RGO is approximately $60 \mathrm{~nm}$, which is in agreement with the morphology observation. The isotherm and pore size distribution (Fig. S1b) of KB indicate that there are two types of pores in its structure with $\sim 6 \mathrm{~nm}$ and $\sim 40$ nm diameters. For G/AC-1, the initial region of the isotherm exhibits a sharper rise at low $P / P_{0}$ compared with that of $\mathrm{KB}$ and $\mathrm{RGO}$, revealing the presence of micropores $(<2 \mathrm{~nm})$, and a hysteresis loop in the $P / P_{0}$ range of $0.5-1.0$ is indicative of mesoporosity $(2-50 \mathrm{~nm}) .[2,22,30]$ From the pore size distribution (Fig. S1c), it can be clearly observed that meso- and micropores with sizes less than several nanometers are dominant in the G/AC-1 structure. The specific surface areas of RGO, KB and G/AC-1 are $285.7 \mathrm{~m}^{2} \mathrm{~g}^{-1}, 1167.5 \mathrm{~m}^{2} \mathrm{~g}^{-1}$ and $1955.6 \mathrm{~m}^{2} \mathrm{~g}^{-1}$, respectively. Note that the surface area of RGO is unexpectedly small. This indicates that the graphene sheets are substantially aggregated or restacked during the drying and reduction process. In the case of G/AC, however, each GO sheet was coated with carbonaceous material arising from glucose and urea. These materials were reduced to RGO/carbon composite particles by the hydrothermal treatment at $150{ }^{\circ} \mathrm{C}$. This process effectively constructs a $3 \mathrm{D}$ structure with graphene sheets as building blocks that prevents restacking. Further activation processes create 
abundant nanopores in G/AC, leading to even larger surface areas. Based on the Barrett-JoynerHalenda (BJH) equation, the pore volumes of RGO, KB and $\mathrm{G} / \mathrm{AC}-1$ are $1.58,1.71$ and 0.07 $\mathrm{cm}^{3} / \mathrm{g}$, respectively.
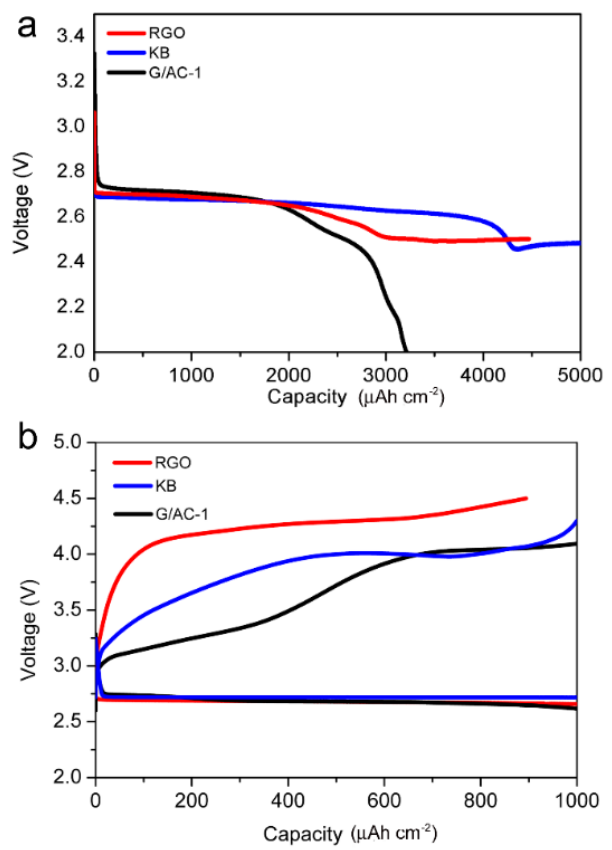

Fig. 2. (a) Discharge curves of $\mathrm{Li}-\mathrm{O}_{2}$ cells using $\mathrm{RGO}, \mathrm{KB}$ and G/AC-1 as oxygen electrodes at $50 \mu \mathrm{Acm}^{-2}$. (b) First curve for the galvanostatic discharge-charge of $\mathrm{Li}-\mathrm{O}_{2}$ cells using RGO, KB and G/AC-1 as oxygen electrodes under a capacity limit of $1000 \mu \mathrm{Ah} \mathrm{cm}^{-2}$ at $50 \mu \mathrm{A} \mathrm{cm}$.

Primary discharge profiles of $\mathrm{Li}_{-} \mathrm{O}_{2}$ batteries using $\mathrm{RGO}, \mathrm{KB}$ and $\mathrm{G} / \mathrm{AC}-1$ cathodes are shown in Fig. 2a at the same current density of $50 \mu \mathrm{A} \mathrm{cm}$. All the cells presented stable voltage plateaus at $2.7 \mathrm{~V}$ during the initial stage, which are in agreement with reported $\mathrm{Li}^{-} \mathrm{O}_{2}$ batteries containing carbon electrodes with/without a metal catalyst. Recent studies have demonstrated that the oxygen reduction reaction (ORR) is insensitive to the presence of catalysts, which suggests that only carbon materials are satisfactory for the discharge process $[6,31]$. For the G/AC-1 cathode, the discharge voltage declined above a capacity of $\square 2000 \mu \mathrm{Ah} \mathrm{cm}^{-2}$, reaching a 
value of $2.0 \mathrm{~V}$ at a capacity of $3200 \mu \mathrm{Ah} \mathrm{cm}^{-2}$. Conversely, the $\mathrm{KB}$ and the RGO cathodes exhibited voltage plateaus at $2.5 \mathrm{~V}$ that continued beyond $4000 \mu \mathrm{Ah} \mathrm{cm}^{-2}$. The discharge capacity of G/AC-1 is obviously lower than that of RGO or KB. KB delivers the highest discharge capacity, which can be attributed to the two types of pores in its structure. The highest pore volume of KB provide more space to accommodate the discharge products, resulting in the highest discharge capacity. The first discharge-charge voltage profiles of those cells are shown in Fig. $2 \mathrm{~b}$ for a fixed capacity of $1000 \mu \mathrm{Ah} \mathrm{cm} \mathrm{cm}^{-2}$ at a current density of $50 \mu \mathrm{A} \mathrm{cm}{ }^{-2}$. All three cathodes showed nearly the same voltage plateau at $2.75 \mathrm{~V}$ during discharge. However, the following galvanostatic charge revealed a significant difference among these cathodes. The charge voltage of RGO steeply increased to a plateau at approximately $4.2-4.3 \mathrm{~V}$. The charge capacity of RGO was less than the discharge capacity because the charging was cut off at $4.5 \mathrm{~V}$ to avoid electrolyte decomposition [14, 26, 32]. In contrast, the charge profile of G/AC-1 showed
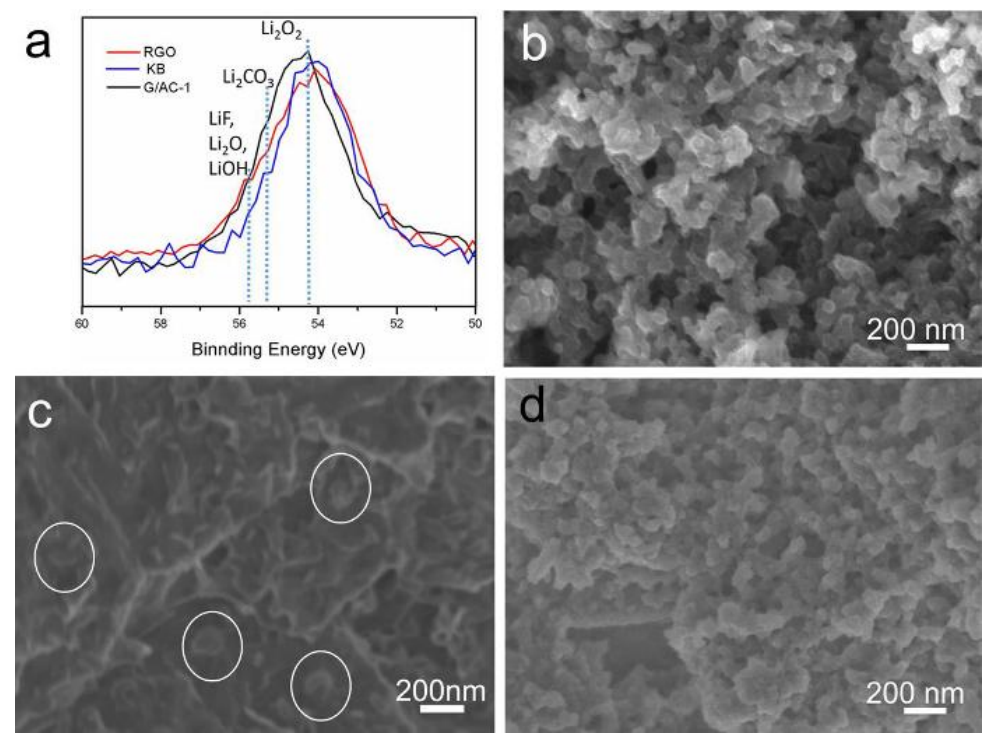

Fig. 3. (a) XPS Li 1s peaks of the discharged cathodes using RGO, KB, and G/AC-1. FESEM images of cathodes using KB (b), RGO (c) and G/AC-1 (d) after discharge at the capacity limit of $1000 \mu \mathrm{Ah} \mathrm{cm} \mathrm{cm}^{-2}$. 
the lowest voltage over the entire range of charge. This was particularly evident during the initial stage of charge, when the charge voltage of $\mathrm{G} / \mathrm{AC}-1(3.1-3.5 \mathrm{~V})$ was considerably lower than those of $\mathrm{KB}$ and RGO.

Because the characteristics of discharge products play an important role in the subsequent charge process $[14,18,33]$, XPS and FESEM were used to investigate the nature and morphology of the cathode deposits after discharge. Three cathode materials were discharged at $50 \mu \mathrm{A} \mathrm{cm}^{-2}$ for 20 hours. Before characterization, the cathodes were washed with TEGDME and dried in a glove box. As can be seen from Fig. 3a, the Li 1s XPS spectra clearly reveal that $\mathrm{Li}_{2} \mathrm{O}_{2}$ is the dominant product for all the three cathodes, although the possible existence of byproducts, such as $\mathrm{Li}_{2} \mathrm{CO}_{3}, \mathrm{Li}_{2} \mathrm{O}$ or $\mathrm{LiOH}$, cannot be excluded. Fig. 3 b presents the FESEM image of KB after discharge, and it is difficult to identify the $\mathrm{Li}_{2} \mathrm{O}_{2}$ deposit on the fine $\mathrm{KB}$ particles. However, when compared with the morphology before discharge (Fig. 1e), the particle size of KB appears to have been enlarged from $\sim 30 \mathrm{~nm}$ to $\sim 100 \mathrm{~nm}$ because of the discharge products $\left(\mathrm{Li}_{2} \mathrm{O}_{2}\right)$. By contrast, the unique sheet-like structure of RGO and G/AC-1 enabled a clear visualization of the $\mathrm{Li}_{2} \mathrm{O}_{2}$ morphology after discharge. As shown in Fig. 3c and Fig. S2, the morphology of $\mathrm{Li}_{2} \mathrm{O}_{2}$ on the RGO surface presents toroidal structures, which is consistent with the reported observations [14]. The toroid particles with diameters of 100-200 nm are isolated from one another, causing an inhomogeneous surface coverage of RGO. For G/AC-1, the FESEM image in Fig. 3d implies that the $\mathrm{Li}_{2} \mathrm{O}_{2}$ particles are much smaller and more homogeneously distributed on the surface than those observed for RGO. This is also consistent with XRD data, as shown in Fig. S3. The XRD peaks from $\mathrm{Li}_{2} \mathrm{O}_{2}$ are clearly observed for $\mathrm{RGO}$, whereas they are greatly reduced for G/AC-1; This suggests that $\mathrm{Li}_{2} \mathrm{O}_{2}$ on $\mathrm{G} / \mathrm{AC}-1$ has a smaller grain size, even $\leq 10 \mathrm{~nm}$, or poorer crystallinity than $\mathrm{Li}_{2} \mathrm{O}_{2}$ on RGO. 
The cycle stability was tested using the capacity-limited cycle method. Fig. 4 and Fig. S4 present typical voltage profiles and capacity vs. cycle number plots for $\mathrm{Li}-\mathrm{O}_{2}$ batteries using RGO, KB and G/AC-1 as the oxygen electrodes. As seen from Fig. 4a and Fig. 4b, at a current density of $50 \mu \mathrm{A} \mathrm{cm}^{-2}$ and a fixed capacity of $500 \mu \mathrm{Ah} \mathrm{cm} \mathrm{cm}^{-2}$, the discharge voltages of RGO and $\mathrm{KB}$ slowly degraded, while the charge voltages rapidly increased to $>4.5 \mathrm{~V}$ after only 9 cycles for RGO and 19 cycles for KB. In contrast, the charge voltage of the battery using G/AC-1 was < 4.5 V for nearly 40 cycles (Fig. 4c). With increasing cycle numbers, the discharge voltage profile exhibited good stability, while the charge voltage increased from $4.2 \mathrm{~V}$ to $4.5 \mathrm{~V}$. It is therefore apparent
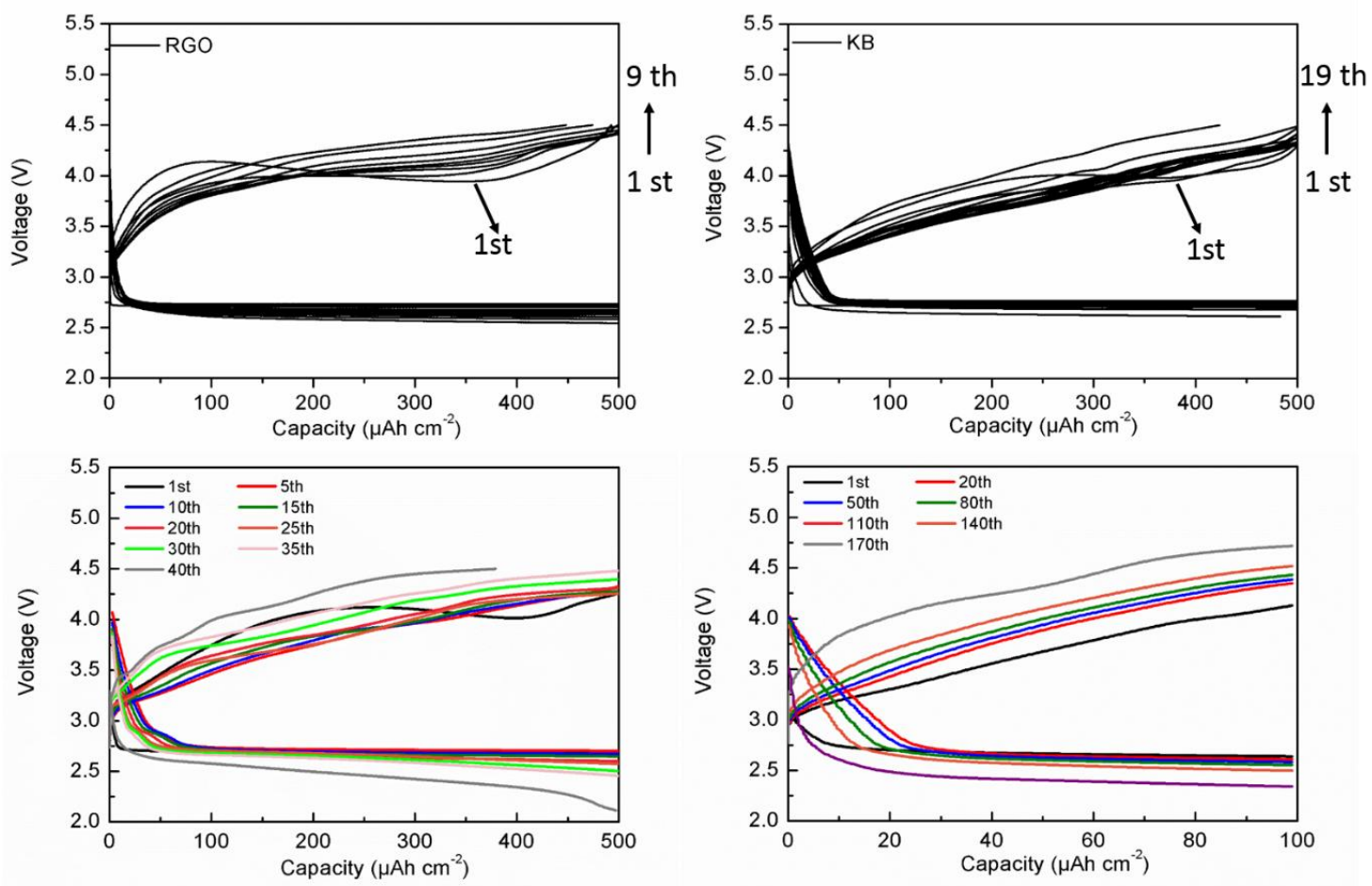

Fig. 4. Discharge-charge cycle performance of $\mathrm{Li}^{-\mathrm{O}_{2}}$ batteries using (a) $\mathrm{RGO}$, (b) $\mathrm{KB}$ and (c) G/AC- 1 cathodes at a fixed capacity of $500 \mu \mathrm{Ah} \mathrm{cm}^{-2}$ and a current density of $50 \mu \mathrm{A} \mathrm{cm}{ }^{-2}$. (d) Discharge-charge cycle performance of $\mathrm{Li}-\mathrm{O}_{2}$ battery using G/AC-1 cathode at a fixed capacity of $100 \mu \mathrm{Ah} \mathrm{cm} \mathrm{cm}^{-2}$ and a current density of $100 \mu \mathrm{A} \mathrm{cm}^{-2}$. 
that G/AC-1 delivers much better cycle stability than that of KB and RGO. When the capacity was fixed to $100 \mu \mathrm{Ah} \mathrm{cm}^{-2}$ at a current density of $100 \mu \mathrm{A} \mathrm{cm} \mathrm{cm}^{-2}$, G/AC-1 could cycle approximately 170 times with a voltage cutoff between $2.0 \mathrm{~V}-4.5 \mathrm{~V}$, as shown in Fig. $4 \mathrm{~d}$. These observations clearly demonstrate that the G/AC-1 cathode considerably lowers the charge overpotential and thus improves the cyclability of the $\mathrm{Li}-\mathrm{O}_{2}$ battery when compared with the other two carbon materials. These results appear to be related to the unique porous structures of G/AC-1 as a "composite material" consisting of graphene sheets coated with activated carbon. In this material, the graphene sheets form a 3D network with good electrical conductivity and excellent mechanical strength and flexibility, while the activated carbon layers provide meso/micropores with diameters of less than several $\mathrm{nm}$ and, thus, a large surface area. There have been many reports that the discharge capacity of a $\mathrm{Li}-\mathrm{O}_{2}$ battery is determined by the complicated interplay between the surface area and the type of pores present. Mesopores, with sizes on the order of several tens of nanometers, are generally regarded as being able to accommodate more discharge products, which increases the discharge capacity $[16,34,35]$. This notion is in agreement with our results shown in Fig. 2a. RGO and KB, with pore sizes of dozens of nanometers, readily delivered much higher discharge capacities. However, their small pores are believed to serve as active sites during discharge, which will enhance the nucleation of $\mathrm{Li}_{2} \mathrm{O}_{2}$ and reduce the particle size. Such a reduction in the $\mathrm{Li}_{2} \mathrm{O}_{2}$ particle size is viewed as an important step in lowering the charge overpotential for the G/AC-1 cathode by greatly reducing the effective current density for the $\mathrm{Li}_{2} \mathrm{O}_{2}$ surface. 

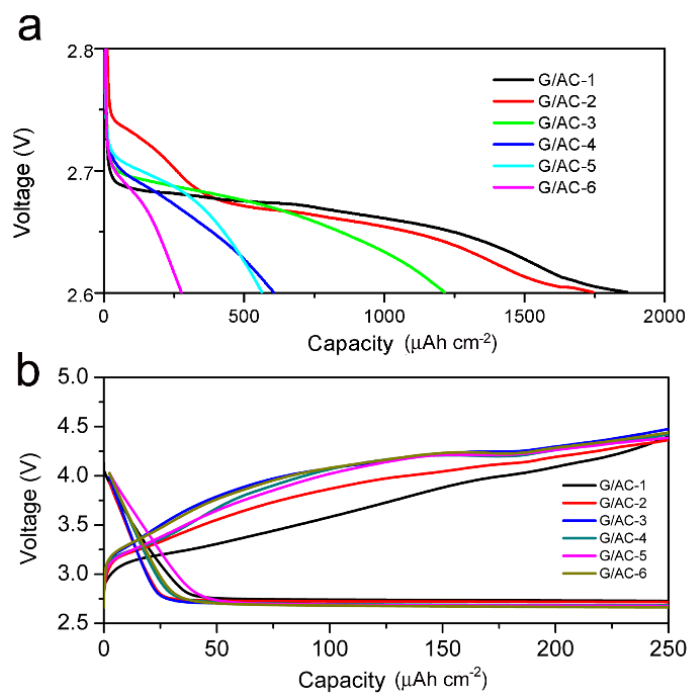

Fig. 5. (a) Discharge curves of $\mathrm{Li}_{2} \mathrm{O}_{2}$ cells using the G/AC series as oxygen electrode materials at $50 \mu \mathrm{A} \mathrm{cm} \mathrm{cm}^{-2}$ and a cutoff potential of $2.6 \mathrm{~V}$. (b) Initial curves for discharge-charge of Li- $\mathrm{O}_{2}$ cells using the G/AC series electrodes under a capacity limit of $250 \mu \mathrm{Ah} \mathrm{cm}^{-2}$ at $50 \mu \mathrm{A} \mathrm{cm}$.

To further evaluate the electrochemical performance of the G/AC materials, we synthesized a series of G/AC samples with different surface areas. The samples were named in series from G/AC-1 to G/AC-6 according to the decreasing weight ratio of AC (Table S1). Nitrogen adsorption-desorption curves for the G/AC series (Fig. S5a) and Table S1 show that the surface area and pore volume decreases with decreasing AC content. The pore size distribution (Fig. $\mathrm{S} 5 \mathrm{~b})$ clearly shows that pores of less than several nanometers are markedly reduced because of decreasing AC content. Fig. 5a shows the discharge profiles of $\mathrm{Li}^{-} \mathrm{O}_{2}$ cells with the G/AC materials as oxygen electrodes at a current density of $50 \mu \mathrm{A} \mathrm{cm} \mathrm{cm}^{-2}$. G/AC-1 delivers the highest discharge capacity of approximately $1800 \mu \mathrm{Ah} \mathrm{cm}^{-2}$ at a cutoff potential of $2.6 \mathrm{~V}$, and the discharge capacities of G/AC materials decrease with surface area (Table S1). Because the structures are similar, the higher discharge capacity of G/AC-1 is clearly beneficial because it has the largest surface area. Furthermore, the greater AC layer on the graphene surface of G/AC- 
1 provides more meso/micropores to act as active sites (or nucleation sites) for the discharge reaction. Fig. 5b presents the first discharge-charge profiles of the $\mathrm{Li}-\mathrm{O}_{2}$ cells with the G/AC cathodes at a current density of $50 \mu \mathrm{A} \mathrm{cm}{ }^{-2}$ for $5 \mathrm{~h}$. The charge voltage decreases with increasing surface area. G/AC-1, which has the highest surface area, exhibits the lowest charge voltage: less than $4.0 \mathrm{~V}$. The rate capabilities of all the $\mathrm{G} / \mathrm{AC}$ cathodes tested from $50 \mu \mathrm{A} \mathrm{cm}^{-2}$ to $250 \mu \mathrm{A} \mathrm{cm}^{-2}$ at a fixed capacity (Fig. S6 and Fig. S7) show the same tendency. The large surface area of G/AC-1 is clearly beneficial for rate performance.
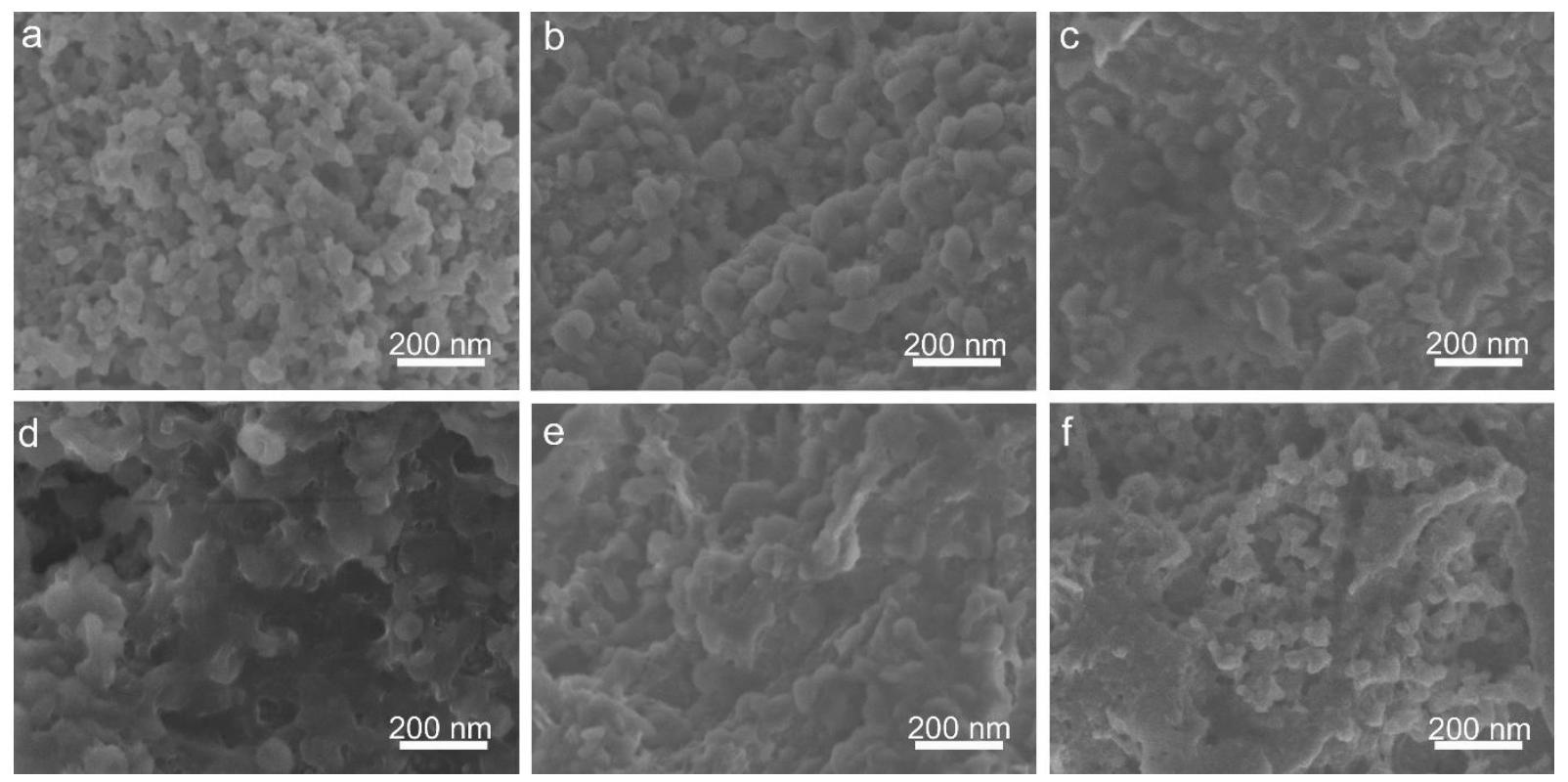

Fig. 6. FESEM images of cathodes using G/AC-1 (a), G/AC-2 (b), G/AC-3 (c), G/AC-4 (d), G/AC-5 (e) and G/AC-6 (f) materials after discharge at $50 \mu \mathrm{A} \mathrm{cm}{ }^{-2}$ and a cutoff potential of 2.6 $\mathrm{V}$.

Fig. 6 presents the morphologies of the G/AC cathodes after discharge. It can be seen that for all samples, the $\mathrm{Li}_{2} \mathrm{O}_{2}$ discharge product was deposited on the electrodes. Tiny nanoparticles with diameters of approximately $10 \mathrm{~nm}$ can be found on the surface of G/AC-1, and the size of the deposited particles increases as the surface area decreases (Table S1). It is interesting that deposited particles that are nearly $100 \mathrm{~nm}$ in size are found on G/AC-4, whose surface area is 
still as high as $1069 \mathrm{~m}^{2} \mathrm{~g}^{-1}$. Even larger particles are observed to be inhomogeneously distributed over the G/AC-6 cathode, which exhibits the smallest surface area. These results further demonstrate that refinement of the $\mathrm{Li}_{2} \mathrm{O}_{2}$ deposition by enhancing nucleation is sufficient to lower the charge overpotential.

\section{Conclusions}

A novel carbon composite material consisting of graphene and activated carbon (G/AC) was synthesized to serve as the cathode for $\mathrm{Li}-\mathrm{O}_{2}$ rechargeable batteries. In the G/AC material, reduced graphene oxide (RGO) forms a 3D network with good electrical conductivity and excellent mechanical strength and flexibility. AC, which covers the graphene surface, provides numerous meso/micropores that are less than several nanometers in size and act as nucleation sites for the discharge products. The AC layers also prevent the graphene sheets from re-stacking, thus preserving the large graphene surface area. This composite structure was found to be quite effective in suppressing the grain growth of $\mathrm{Li}_{2} \mathrm{O}_{2}$ that occurred in the pristine $\mathrm{RGO}$ cathode. The $\mathrm{Li}_{2} \mathrm{O}_{2}$ grains became much smaller $(\sim 10 \mathrm{~nm})$ and were distributed more homogeneously in the G/AC cathode, whereas toroidal particles as large as 100-200 nm were observed in the RGO cathode. The charge voltage for the G/AC cathode was gradually increased from $\sim 3 \mathrm{~V}$ to $4 \mathrm{~V}$, while that for the RGO cathode showed a steep increase to a plateau at $4.2-4.3 \mathrm{~V}$ and finally exceeded 4.5 V. The G/AC material deliver the discharge capacity of $1800 \mu \mathrm{Ah} \mathrm{cm}^{-2}$. Most important, the G/AC cathode also exhibited much better cyclability than the RGO. These observations demonstrate that the reduction in the $\mathrm{Li}_{2} \mathrm{O}_{2}$ particle size resulting from enhanced nucleation effectively lowers the charge overpotential and improves the cyclability in the Li- $\mathrm{O}_{2}$ batteries. Although more studies are required to further improve the discharge capacities and rate 
capabilities of the G/AC materials, we believe that these materials are promising candidate highperformance oxygen-electrode materials for use in $\mathrm{Li}-\mathrm{O}_{2}$ batteries.

\section{Acknowledgments}

This work was partly supported by the ALCA-SPRING of JST and by the MEXT Program for the Development of Environmental Technology using Nanotechnology.

\section{References}

[1] Guo Z, Zhou D, Dong X, Qiu Z, Wang Y, Xia Y. Ordered hierarchical mesoporous/macroporous carbon: A high-performance catalyst for rechargeable $\mathrm{Li}-\mathrm{O}_{2}$ batteries. Adv Mater 2013; 25 (39):5668-5672.

[2] Wang ZL, Xu D, Xu JJ, Zhang LL, Zhang XB. Graphene oxide gel-derived, free-standing, hierarchically porous carbon for high-capacity and high-rate rechargeable $\mathrm{Li}-\mathrm{O}_{2}$ batteries. Adv Funct Mater 2012; 22(17):3699-3705.

[3] Ogasawara T, Débart A, Holzapfel M, Novák P, Bruce PG. Rechargeable $\mathrm{Li}_{2} \mathrm{O}_{2}$ electrode for lithium batteries. J Am Chem Soc 2006; 128(4):1390-1393.

[4] Abraham K, Jiang Z. A polymer electrolyte-based rechargeable lithium/oxygen battery. J Electrochem Soc 1996; 143(1):1-5.

[5] Bruce PG, Freunberger SA, Hardwick LJ, Tarascon J-M. Li-O $\mathrm{O}_{2}$ and Li-S batteries with high energy storage. Nat Mater 2012; 11(1):19-29.

[6] Lu YC, Xu Z, Gasteiger HA, Chen S, Kimberly HS, Yang SH. Platinum-gold nanoparticles: A highly active bifunctional electrocatalyst for rechargeable lithium-air batteries. J Am Chem Soc 2010; 132(35):12170-12171.

[7] Hu X, Han X, Hu Y, Cheng F, Chen J. $\varepsilon-\mathrm{MnO}_{2}$ nanostructures directly grown on Ni foam:a cathode catalyst for rechargeable $\mathrm{Li}^{-} \mathrm{O}_{2}$ batteries. Nanoscale 2014; 6(7):3522-3525. 
[8] Guo K, Li Y, Yang J, Zou Z, Xue X, Li X, et al. Nanosized Mn-Ru binary oxides as effective bifunctional cathode electrocatalysts for rechargeable $\mathrm{Li}-\mathrm{O}_{2}$ batteries. J Mater Chem A 2014; 2:1509-1514.

[9] Li J, Wang N, Zhao Y, Ding Y, Guan L. $\mathrm{MnO}_{2}$ nanoflakes coated on multi-walled carbon nanotubes for rechargeable lithium-air batteries. Electrochem Commun 2011; 13(7):698-700.

[10] Peng Z, Freunberger SA, Chen Y, Bruce PG. A reversible and high rate Li- $\mathrm{O}_{2}$ battery. Science 2012; 337(6094):563-566.

[11] Lim HD, Park KY, Song H, Jang EY, Gwon H, Kim J, et al. Enhanced power and rechargeability of a $\mathrm{Li}_{-} \mathrm{O}_{2}$ battery based on a hierarchical-fibril CNT electrode. Adv Mater 2013; 25(9):1348-1352.

[12] Chen Y, Li F, Tang DM, Jian Z, Liu C, Golberg D, et al. Multi-walled carbon nanotube papers as binder-free cathodes for large capacity and reversible non-aqueous $\mathrm{Li}-\mathrm{O}_{2}$ batteries. $\mathrm{J}$ Mater Chem A 2013; 1(42):13076-13081.

[13] Cui Z, Fan W, Guo X. Lithium-oxygen cells with ionic-liquid-based electrolytes and vertically aligned carbon nanotube cathodes. J Power Sources 2013; 235:251-255.

[14] Mitchell RR, Gallant BM, Thompson CV, Yang SH. All-carbon-nanofiber electrodes for high-energy rechargeable $\mathrm{Li}_{2} \mathrm{O}_{2}$ batteries. Energ Environ Sci 2011; 4(8):2952-2958.

[15] Zhang G, Zheng J, Liang R, Zhang C, Wang B, Hendrickson M, et al. Lithium-air batteries using SWNT/CNF buckypapers as air electrodes. J Electrochem Soc 2010; 157(8):A953-A956. [16] Mirzaeian M, Hall PJ. Preparation of controlled porosity carbon aerogels for energy storage in rechargeable lithium oxygen batteries. Electrochim Acta 2009; 54(28):7444-7451.

[17] Li Y, Wang J, Li X, Geng D, Li R, Sun X. Superior energy capacity of graphene nanosheets for a nonaqueous lithium-oxygen battery. Chem Commun 2011; 47(33):9438-9440. 
[18] Sun B, Wang B, Su D, Xiao L, Ahn H, Wang G. Graphene nanosheets as cathode catalysts for lithium-air batteries with an enhanced electrochemical performance. Carbon 2012; 50(2):727733.

[19] Xiao J, Mei D, Li X, Xu W, Wang D, Graff GL, et al. Hierarchically porous graphene as a lithium-air battery electrode. Nano lett 2011; 11(11):5071-5078.

[20] Yoo E, Zhou H. Li-air rechargeable battery based on metal-free graphene nanosheet catalysts. ACS nano 2011; 5(4):3020-3026.

[21] Jung HG, Hassoun J, Park JB, Sun YK, Scrosati B. An improved high-performance lithiumair battery. Nat Chem 2012; 4(7):579-585.

[22] Beattie S, Manolescu D, Blair S. High-capacity lithium-air cathodes. J Electrochem Soc 2009; 156(1):A44-A47.

[23] Xu JJ, Wang ZL, Xu D, Zhang LL, Zhang XB. Tailoring deposition and morphology of discharge products towards high-rate and long-life lithium-oxygen batteries. Nat Commun 2013; $4: 2438$.

[24] Lu J, Lei Y, Lau KC, Luo X, Du P, Wen J, et al. A nanostructured cathode architecture for low charge overpotential in lithium-oxygen batteries. Nat Commun 2013; 4:2383.

[25] Yang J, Zhai D, Wang HH, Lau KC, Schlueter JA, Du P, et al. Evidence for lithium superoxied-like species in the discharge product of a $\mathrm{Li}-\mathrm{O}_{2}$ battery. Phys Chem Chem Phys 2013; 15(11):3764-3771.

[26] Zhai D, Wang HH, Yang J, Lau KC, Li K, Amine K, et al. Disproportionation in $\mathrm{Li}^{-\mathrm{O}_{2}}$ batteries based on a large surface area carbon cathode. J Am Chem Soc 2013;135(41):1536415372. 
[27] Guo S, Dong S. Graphene nanosheet: synthesis, molecular engineering, thin film, hybrids, and energy and analytical applications. Chem Soc Rev 2011; 40(5):2644-2672.

[28] Sun Y, Wu Q, Shi G. Graphene based new energy materials. Energ Environ Sci 2011; 4(4):1113-32.

[29] Zhou X, Liu Z. A scalable, solution-phase processing route to graphene oxide and graphene ultralarge sheets. Chem Commun 2010; 46(15):2611-2613.

[30] Ottakam Thotiyl MM, Freunberger SA, Peng Z, Bruce PG. The carbon electrode in nonaqueous Li-O2 cells. J Am Chem Soc 2012; 135(1):494-500.

[31] Lu YC, Gasteiger HA, Crumlin E, McGuire R, Yang SH. Electrocatalytic activity studies of select metal surfaces and implications in Li-air batteries. J Electrochem Soc 2010; 157(9):A1016-A1025.

[32] McCloskey B, Bethune D, Shelby R, Girishkumar G, Luntz A. Solvents' critical role in nonaqueous lithium-oxygen battery electrochemistry. J Phys Chem Lett 2011; 2(10):1161-1166.

[33] Gallant BM, Mitchell RR, Kwabi DG, Zhou J, Zuin L, Thompson CV, et al. Chemical and morphological changes of $\mathrm{Li}_{2} \mathrm{O}_{2}$ battery electrodes upon cycling. J Phys Chem C 2012; 116(39):20800-20805.

[34] Younesi SR, Urbonaite S, Björefors F, Edström K. Influence of the cathode porosity on the discharge performance of the lithium-oxygen battery. J Power Sources 2011; 196(22):98359838.

[35] Williford RE, Zhang JG. Air electrode design for sustained high power operation of Li/air batteries. J Power Sources 2009; 194(2):1164-1170. 